\title{
Langerhans Cell Histiocytosis in a Five-Month-Old Infant
}

Chi MH', Cheng $\mathrm{CD}^{1}$ and Yeh $\mathrm{TC}^{2 *}$

${ }^{1}$ Department of Pediatrics, Hsinchu Cathay General

Hospital, Taiwan

${ }^{2}$ Division of Hematology \& Oncology, Mackay Children's Hospital, Taiwan

*Corresponding author: Yeh TC, Division of

Hematology \& Oncology, Mackay Children's Hospital, 92

Sec. 2, Chung-San North Road, Taipei, Taiwan

Received: J anuary 04, 2019; Accepted: February 11, 2019; Published: February 18, 2019

\section{Keywords}

Langerhans cell histiocytosis; Enlarged phalangeal bone; Granulation tissue

\section{Clinical Image}

A well-nourished 5-month-old boy presented with a 4-week history of swelling in his right middle finger. Physical examination did not find hepatosplenomegaly or lymphadenopathy, but an enlarged phalangeal bone (Figure 1). Laboratory examinations were within normal limits. X-ray examination revealed an isolated expansile lytic bone lesion without cortical destruction or periosteal

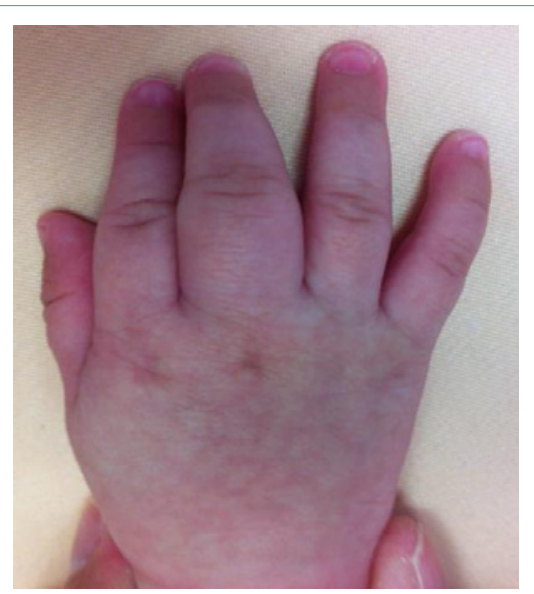

Figure 1: Langerhans cell histiocytosis.

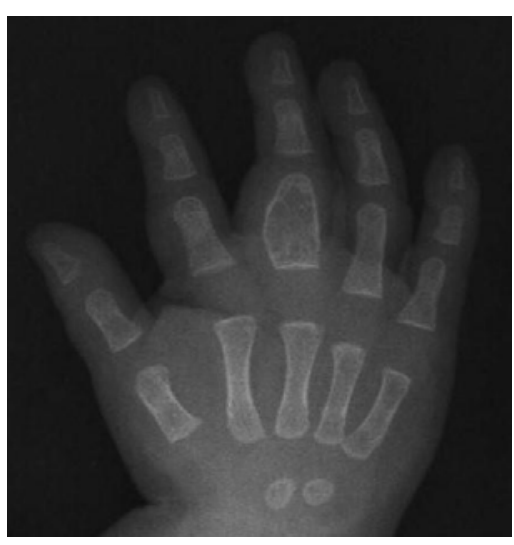

Figure 2: X-ray imaging of the right middle finger showing an isolated expansile lytic bone lesion in the proximal phalanx of the right middle finger.

reaction from metaphysis or diaphysis in the proximal phalanx of the right middle finger (Figure 2). Fine needle aspiration cytology was performed suggestive of an inflamed granulation tissue with atypical cells displaying irregular nuclei and ample cytoplasm. Immunohistochemical study of the atypical cells showed positive staining of CD1a, CD5, CD68 (KP1), Langerin, S-100 protein, and negative staining of $\mathrm{CD} 20$. The findings confirmed the diagnosis of Langerhans cell histiocytosis. The patient did not receive any treatment, but routine follow-up. One year later, the patient was asymptomatic and in good health. 